http://dx.doi.org/10.4314/gjl.v6i2.4

\title{
THE STRUCTURE OF FACE-TO-FACE CASUAL CONVERSATION AMONG THE AKANS
}

\author{
Felix Kpogo and Kofi Busia Abrefa
}

\begin{abstract}
The social act of conversation passes through routine procedures before it is achieved. This paper tries to find out the structure of face-to-face casual conversation openings and closings among the Akans. It also seeks to juxtapose the structure of face-to-face conversation to that of telephone conversation as proposed by Coronel-Molina (1998). 20 dyads of natural conversation from the residents of Amamoma are sampled for the study. Recordings of the conversations of residents of the community serve as the corpus for analysis of the study. The study considers the structure of openings in two forms: presence and absence of interlocutors, and that in whichever case we could have greetings and how-are-you sequence. The identification and recognition sequence only occurs in the absence of interlocutors. However, the closing section of conversations are categorized into three: introductory closings announcing closure and new topic introduction/recapitulation, intermediate closings - future arrangements and transmitted greetings, and final closings - terminal exchanges. Also, even though conversations occur across different modes, that is, face-to-face and telephone, there seem to be some sort of generality and universality in the structures of conversation (especially, openings) that occur through those media.
\end{abstract}

Keywords: Conversational analysis, conversational participant, dyad, topic, terminal exchange.

\section{Résumé}

L'acte social de conversation traverse des procédures de routine avant qu'il soit accompli. Ce papier essaie de découvrir la structure d'ouvertures de conversation familière face à face décontractées et de fermetures parmi les Akans. Il cherche aussi à juxtaposer la structure de conversation face à face à celle de conversation téléphonique comme 
proposée par Coronel-Molina (1998). 20 données d'enregistrement de conversation naturelles des résidents d'Amamoma sont essayées pour l'étude. Les enregistrements des conversations de résidents de la communauté servent du corpus pour l'analyse de l'étude. L'étude considère la structure d'ouvertures dans deux formes : la présence et l'absence d'interlocuteurs et par n'importe cas dans lequel nous pourrions avoir des salutations et un ordre "comment allez-vous". L'ordre de reconnaissance et d'identification se produit seulement faute des interlocuteurs. Cependant, la section finale de conversations sont classés par catégories en trois : fermetures préliminaires - annonce de la fermeture et la nouvelle introduction/récapitulation de thème, les fermetures intermédiaires - dispositions futures et salutations transmises et fermetures finales - échanges terminaux. Aussi, même si les conversations se produisent à travers de différents modes, face à face et au téléphone, il semble y avoir une sorte de généralité et universalité dans les structures de conversation (surtout, les ouvertures) qui se produisent par ces médias.

\section{Introduction}

Language serves as the most potent tool for communication and it is unique to humans. Communication, is however, seen as a "transactional process of creating meaning". By 'transactional process', it is considered as "one in which those persons communicating are mutually responsible for what occurs" (Verderber, 1981: 4). Communication is therefore not a one-party phenomenon; rather, it ensues between two or more individuals. Communication taking place means that individuals are involved in a conversation since there is turn-taking or allocation of turns at reasonable intervals among conversational participants (CPs). Conversations are never the same even if CPs are conversing about the same conversational topic. However, there are certain components in a conversation that will appear very alike or completely alike in social interaction. A very good example is the way conversations begin and the way they end. According to Kiss (2002: 2), conversation is a string of at least two turns produced by different speakers. In it, only a speaker is supposed to speak at a time. Conversations do not just start and end; they go through series of procedures or sequences before some required information is transmitted among CPs. These sequences are what conversational analysts are particularly interested in, whether in institutional talk (for example, in doctor-patient interaction) or in everyday interaction. According to Paltridge (2008: 107), conversational analysis (hereinafter CA) is an approach to the analysis of spoken discourse that looks at the way people manage their everyday 
conversational interactions. The focal point of CA is talk, and it extends to non-verbal aspects of interaction. CA therefore examines how spoken discourse is structured as speakers carry out the interaction (Silvia 2012). Conversational Analysts have digested conversational structure in different domain such as CA, sociolinguistics, pragmatics, stylistics etc. (see Schegloff 1986; 1973 with Sacks; 1979; Hopper 1989; Placencia 1997; Coronel-Molina 1998; Taleghani-Nikazm 2002 etc.).

Initiating and ending conversations are some of the many ways that individuals can have a social relationship started, broken or maintained. This implies that the way individuals open or close conversations are very important in one's social life. Opening, as well as closing a conversation goes through an elaborate ritual before the initiation or closing is achieved. It could however vary from one person to another due to the kind of relationship that exists between CPs.

It is apparent that communication goes through a series of procedures regardless of the mode of communication. For instance, whether in face-to-face, telephone, or in internet chatrooms, one will have to go through the routine of opening and closing in an automated manner.

Researchers like Schegloff (1968; 1979; 1986), Schegloff and Sacks (1973) and Jefferson (1984) introduced the study of telephone conversations while others like Calvo (1995), Coronel-Molina (1998) and Taleghani-Nikazm (2002), Sun (2005), Raclaw (2008), Prace (2009) and Bon-Franch (2011) researched into opening and closing through different mediums, especially in telephone calls and internet chatrooms. These researchers have proposed a canonical order for either opening or closing, trying to either justify or denounce the earlier proposal by researchers like Schegloff $(1968 ; 1979 ; 1986)$, and Schegloff and Sacks (1973). However, to the best of our knowledge, there has not been any such works on face-to-face conversations either in Akan or other related languages that proposes any canonical sequence for conversations in general, though conversations began through the face-to-face medium even before the emergence of technology.

It is in this regard that the present researchers seek to juxtapose the structure of face-to-face casual conversation openings and closings in Akan to that of telephone calls to ascertain the relationship between the structures of the two modes of conversation.

\section{Theoretical Framework}

Coronel-Molina's (1998) theory of telephone conversation is adopted for the analysis in this paper. The framework is a further development of Schegloff (1986) and Schegloff and Sack (1973). His framework attempts to identify telephone conversations; specifically, if there appears to be a standard formula used in beginning 
a telephone conversation as suggested by Schegloff. The framework also identifies if CPs of a telephone conversation move immediately to the purpose of the call or they do follow a pattern of information exchange before the real conversation begins among others. Coronel-Molina (1998) in trying to explain the fundamentals of his framework put things into two perspectives. First, he considers how many of the categories for openings (Schegloff, 1986) and closings (Schegloff and Sacks, 1973) appeared in his data. Second, he considers how closely his information fit with the extant theories of universal functions.

Like Schegloff (1986), Coronel-Molina postulates summons/answer, identification/recognition, greeting tokens and initial inquiries 'how-are-you' and answer. In conversational closings, he explains that closing of conversations were difficult to determine because Schegloff and Sacks (1973: 303-304) identified markers like "pre-closing" or indicators that show that one participant is ready to terminate the conversational process but he/she is offering the other participant the opportunity to open another topic. Schegloff and Sacks (1973) did not create any specific model to indicate these indicators other than the pre-closings. However, Coronel-Molina (1998) gave precise names of such kinds of indicators that were used to terminate Spanish telephone conversations. He called these closing indicators in addition to that of Schegloff and Sack's pre-closings as new topic introduction, recapitulation and final closing. New topic introduction simply refers to an introduction of a new topic of conversation after a pre-closing gambit. For recapitulation, it involves a brief summarizing of topics discussed and/or arrangements made.

Coronel-Molina (1998) claims that though the four opening sequences identified by Schegloff (1986) and the four closing sequences he (Coronel-Molina) identified recur constantly in conversations, such closing sequences may not occur in Schegloff's canonical order. Coronel-Molina, having identified the canonical order for openings and closings, posits that in general, there are close correspondences in conversations in telephone calls, although not necessarily exact matches between the predicted categories and what appears in his framework. In this regard, he then argues that the correspondences support the idea of universal functions in telephone conversations across cultures while there also remain reflections of cultural differences.

\section{Methodology}

The study employed a qualitative research design. This was chosen because the research is aimed at bringing out a deeper knowledge of a social structure, that is, casual conversational openings and closings among the Akan. The setting of the study is the 
Akan society, specifically, Amamoma, Cape Coast, Ghana. Twenty (20) dyads of natural conversations were collected. The 20 dyads of natural conversations were not only collected from the indigenes of Amamoma but also from other people like students and lecturers who are Akans and live within the community. Thus, though majority of the data came from Fante, the main dialect of the community, a few came from the Asante-Twi, and these have been indicated in the introductory information about the dyads that contain such data.

The simple random sampling technique was used in collecting the twenty (20) dyads of naturally occurring conversation. This technique was employed because they consider every member of the target population as having an equal chance to be selected for the study. Every member of the community is seen by the researchers as initiating and ending conversations and that has necessitated this sampling technique in gathering the data. A recorder was used to audio-tape the 20 dyads of natural conversations. In the process of data collection, the recorder was used to tap the conversation when CPs were very close to the researchers. In cases where the recorder could not capture the conversation well as a result of distance, recording was done through writing. The recorded data helped determine the structure of face-to-face conversational openings and closings.

The data was collected within two periods: the first, from the $25^{\text {th }}$ December, 2013 to $2^{\text {nd }}$ January, 2014; the second, from March 6 to March 28, 2014. The researchers recorded the conversations without the knowledge of the interlocutors in order not to influence the conversation. This is because the researchers wanted naturally occurring data. Nonetheless, the CPs were later prompted that their conversation was recorded and that they were going to be used for a study. The data for the analysis, however, came from only those who gave the permission for their conversation to be used for the study. Data from those who did not give their consent were rejected.

In order for the data to be presented naturally, Jefferson's (1984: ix-xvi) conventions for transcribing spoken data were employed. These conventions for transcribing spoken discourse (where applicable) were used to compliment the speeches in the written text.

Below are some of Jefferson's conventions for transcribing spoken data employed in the data transcription.

Symbol

hh
Name

Use

- Audible exhalation/outbreath 


$\begin{array}{lll}::: & \text { Colon(s) } & \begin{array}{l}\text { - Speaker stretches the } \\ \text { preceding sound } \\ \text { or letter }\end{array} \\ \text { ((italic text) }) & \text { Double Parentheses } & \begin{array}{l}\text { - Annotation of non-verbal } \\ \text { activity }\end{array} \\ / / & \text { Slashes } & \text { - Overlap } \\ \text { ALL CAPS } & \text { Capitalized text } & \begin{array}{l}\text { - Indicates shouted or } \\ \text { increased } \\ \text { volume speech }\end{array}\end{array}$

\section{Analysis}

The structure of face-to-face openings, per our data, could broadly be grouped into two: presence of interlocutors and absence of interlocutors. Though both forms have greetings and how-are-you sequences, the identification and recognition sequence precedes the greetings and how-are-you sequences in the absence of interlocutors. In relation to the conversational closings, we shall discuss announcing closure, new topic introduction or recapitulation, future arrangement and transmitted greeting, and terminal exchanges. It is important to note that the sequences for various openings and closings usually do not all occur at the same time in a conversation - they do not appear in a strict orderly pattern even though those that occur are perfunctory.

\subsection{Structure of face-to-face casual conversational openings}

\subsubsection{Presence of interlocutors}

In dyadic face-to-face casual conversations, there are many cases where both conversational participants are in sight before a conversation begins. This could happen in the case where one or both conversational participants are approaching each other from a distance and eventually meet at a point. From the data, in cases where both participants are in sight, conversational participants begin with an interrogation or any form of address term to signal the commencement of the conversation. The example below shows a situation where both conversational participants were in sight and an interrogation is used to signal one of the participants to demonstrate the initiation of a talk:

Dyad (1): A conversation between a trader and a customer, where the trader appears and meets the customer in front of her house.

$$
\text { Trad. }=\text { Trader, Cust. }=\text { Customer }
$$




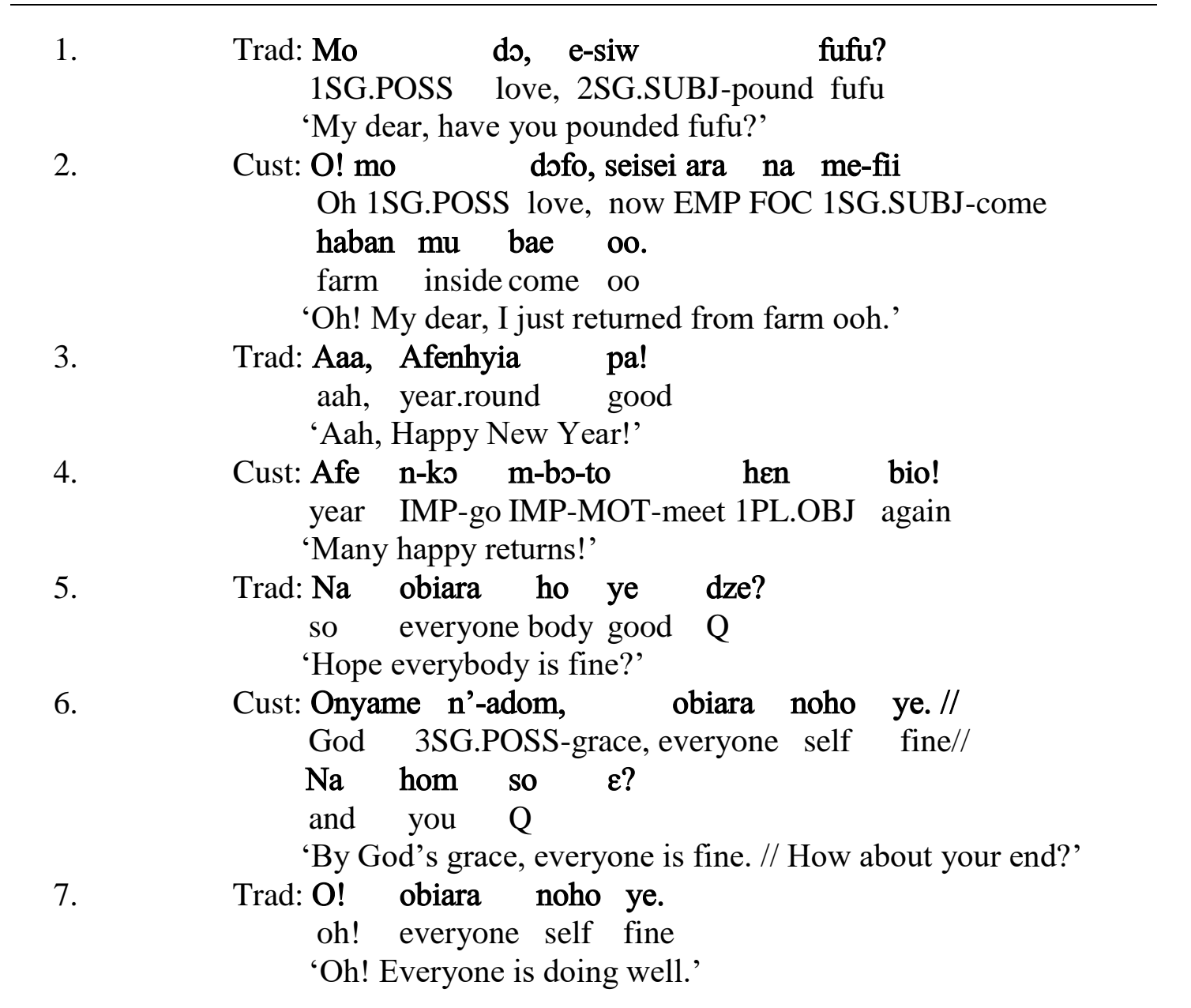

From the example above, it is obvious that both conversational participants, the trader and the customer, were present as they eventually met in front of a house. Within this context of face-to-face opening, the CPs exchanged the adjacency pair of greetings and the how-are-you sequences. But we can see that prior to the greetings and how-areyou sequence there was some fraternal exchangers between the CPs to initiate the conversation. Specifically, we can see that the addresser, the trader who commenced the conversation, began with an interrogation so as to draw the addressee's attention in order to advance the talk. And this is quite common among the Akans. Sometimes, depending on the relationship between the CPs, some kind of fraternal discussion may precede the greetings and how-are-you sequence.

According to Firth (1972: 1), greeting is the recognition of an encounter as socially acceptable. The significance of greetings among the Akans, as a culturally distinct group cannot be underestimated. They view greetings not just as a merely social 
phenomenon but rather a socio-cultural phenomenon that binds them as a cultural group to depict a sense of belonging. This is why we do not entirely agree with Malinowski's (1926) view that greetings form part of exchanges in which words are used merely to maintain ties of union or human relationships. Evidence from our data indicates that greetings perform a wide range of sociolinguistic functions such as showing politeness, displaying affection or a sense of belonging to conversational partners. It is in this respect that we argue that greetings perform a social function of promoting social cohesion, and can therefore be differentiated from other adjacency pairs like questionsand-answers as they basically seek to give real information. The form of greeting and responses such as the one in dyad (1) above or the example below is present in the data:

8.

$$
\begin{array}{lll}
\text { A: Me-ma } & \text { wo } & \text { akye! } \\
\text { 1SG.SUBJ-give } & \text { 2SG.OBJ morning } \\
\text { 'Good morning!' } & &
\end{array}
$$

9.

$$
\begin{aligned}
& \text { B: Yaa anua/Yaa oba } \\
& \text { response brother/sister/child } \\
& \text { 'Good morning, my brother/sister/child.' }
\end{aligned}
$$

The above greeting exchanges that occur even in cases where the conversational participants are not blood related demonstrates how Akans as a culturally-minded group of people solidify ties among themselves.

The how-are-you sequence is the point which marks the end of the initiation process of a conversation. In the how-are-you sequence, conversational participants inquire about the well-being of each other. After a set of how-are-you has been exchanged, as Schegloff (1986) indicates, the initiator of the conversation uses the anchor position to introduce the first topic as the example below portrays.

Dyad (2): A conversation between two strangers who meet at a point $\mathrm{S} 1=\mathrm{Stranger} 1$, $\mathrm{S} 2=$ Stranger 2.

10. S1: shembaa, me-ma wo afrinhyia pa! queen, 1SG.SUBJ-give 2SG.OBJ year.round good 'Dear, Happy New Year!'

11. S2: Afe n-ko m-bo-to hen! year IMP-go IMP-MOT-meet 1PL.OBJ 'Many happy returns!'

12. S1: Na me-pa wo so 1SG.SUBJ-beg 2SG.OBJ beg 2SG.POSS body good Q 
'Please, how are you doing?'

13. S2: Nyame n'-adaworoma, mo ho ye. God 3SG.POSS-grace, 1SG.POSS body good 'By the grace of God, I'm fine.'

14. S1: Ye-da Onyame ase.// Me-pa wo kyew, 1SG.SUBJ-lie God under. 1SG.SUBJ-beg 2SG.OBJ beg, hemfa na mo-bo-hu 'Methodist pastor' no? where FOC 1SG.SUBJ-FUT-see Methodist pastor DEF? I-bo-tum dze m-a-ko ho a? 2SG.SUBJ-FUT-able take 1SG.SUBJ-CONS-go there Q

'We thank God. // Please, where can I find the Methodist pastor? Can you take me there?'

It can be observed from both dyad (1) and (2) that the how-are-you sequence immediately follows the greetings sequence. In fact, though usually conversational openings of strangers are mostly interactionally compact, the how-are-you sequence was exchanged as if they knew each other already. It could be that the addresser, Speaker 1, used this strategy to win favour from the addressee so that she could return the favour by honouring her request; it was either she was influenced by her religious teachings of showing care and compassion to everyone, or she was just communicatively competent.

One thing that is prevalent in the data is that, after conversational participants have inquired about the well-being of each other, they extend the inquiries to other members of the family. A clear case of that is the example in dyad (1) above where CPs inquired about the well-being of themselves and their respective families altogether. This phenomenon was also present in Teleghani-Nikazm (2002), where he posited that for Iranians, it was not enough for a participant to inquire about only a co-participant's well-being, rather, the how are you sequence was extended to the families of the conversational participants. Some studies have claimed that the how are you sequence is an instance of phatic communion. As quoted in Saadah (2009), phatic communion refers to a type of speech people get involved to create ties of union which merely fulfil a social function, and it is a term attributed to Malinowski (1923). We, however, disagree with this assertion because Akans, as a culturally-minded people, extend the inquiries about the well-being of CPs to their respective families to show a sense of belonging and oneness and not to 'merely' fulfill a social function. 


\subsubsection{Absence of an interlocutor}

The absence of interlocutor happens in cases where one of the participants of the yet to be started conversation is not in sight. When that happens, the conversational participant making the approach will summon the other person to assume a participant position. This is what we refer to as identification and recognition. This refers to a situation where a conversational participant (who has been summoned) tries to find out the addresser who is addressing him/her. Sometimes, the addressee is able to assume correctly, using the voice of the addresser to detect who the addresser is. In that regard, the addresser will only have to confirm or deny the claim of the addressee. An example of such form of identification and recognition is what is seen in dyad (3) below. In cases of such nature, the addresser or "summoner" does that by addressing the person by name - first or last name. After the summons, the response makes the "summonee" assume a participant position in the conversation. An example of such a discourse is demonstrated below.

Dyad 3: A conversation between two siblings; Nana and Ekuwa. Nana was approaching from afar.

15. Nana: Sista Ekuwa e:::!

sister Ekuwa PART

'Sister Ekuwa e!'

16.

Ekuwa: Ye:::s!//Na woana koraa na $\varepsilon$-re-fre

yes// so who even FOC 3SG-PROG-call

me ewia dem yi?

1SG.OBJ sun that DEF

'Y:::es! // So who's calling me this sunny afternoon?'

17. Nana: o-ye m-ara.

3SG.SUBJ-be 1SG.OBJ-EMPH

'It's me.'

18. Ekuwa: Aaa, Nana?

PART, Nana

'Aah, Nana?'

19. Nana: Nyew oo // $\mathrm{Na}$ wo ho ye dze?

yes PART and 2SG.POSS.body good EMPH

'Yes oh // Hope you are fine?'

20.

Ekuwa: Nyame n'adom, mo ho ye.

God 3SGPOSS.grace, 1SG.POSS.body good 
21.

Nana: Mbofra no $\varepsilon$ ?

children DEF Q

'How about the children?'

22.

\begin{tabular}{|c|c|}
\hline Ekuwa: Obiara & no ho ye. // Me-gye \\
\hline everyone & 3SG.POSS.body good// 1SG.SUBJ-receive \\
\hline $\mathrm{dzi} d \varepsilon$ & nde dze, Ata no \\
\hline
\end{tabular}

23.

$\begin{array}{clll}\text { Nana: Nde dze, o-ye } & \text { papaapa./ } & \mathrm{Na} \\ \text { today EMPH, } & \text { 3SG.SUBJ-good very // } & \text { and } \\ \text { (-a-nn-ko } & \text { beebiara nde? } & \end{array}$

ø-a-nn-ko

beebiara nde?

(2SG.SUBJ)-PST-NEG-go anywhere today

'As for today, he's very fine. // Didn't you go anywhere today?'

In dyad (3), the addresser or "summoner", Nana, who was approaching from afar, summoned the "summonee", Ekuwa, who was out of sight (Ekuwa was indoors). In this context, it was apparent that the last resort that the summoner or addresser could rely on was Ekuwa's name, in order to bring the summonee into sight for the conversation to continue. It is also clear that since the persons who would want to assume the role of conversational participants are physically absent, one of the two create that enabling environment to set the conversation rolling. This situation is similar to what happens in a telephone conversation.

Within the context of absence of an interlocutor, evidence from our data indicates that greetings and how-are-you sequences do not occur concurrently in a single conversation. In many cases, the how-are-you sequence occurred but greetings were absent. It is only in one situation that both sequences did not occur at all, that is in dyad (4) below. This particular scenario in dyad (4) could be due to the fact that both CPs have had an earlier encounter (probably in the course of that day), hence, making the openings brief. Greetings and how-are-you sequences occurred in both the presence and absence of an interlocutor; conversely, identification and recognition, was only evident in the absence of an interlocutor.

Also, from the data, there were some cases where after the addressee had inquired of the addresser, the addresser went ahead and mentioned his/her name. This occurrence, made the identification and recognition process brief and concise. The brief and concise identification and recognition paved way for the addresser, to proceed to the reason for her visit. An example of such form of a conversation is that which ensued between Ekuwa and her customer (Amelia) as evident in dyad (4) below: 
Dyad (4): A conversation between a trader (Ekuwa) and a customer (Amelia). Ekuwa was indoors as Amelia comes around.

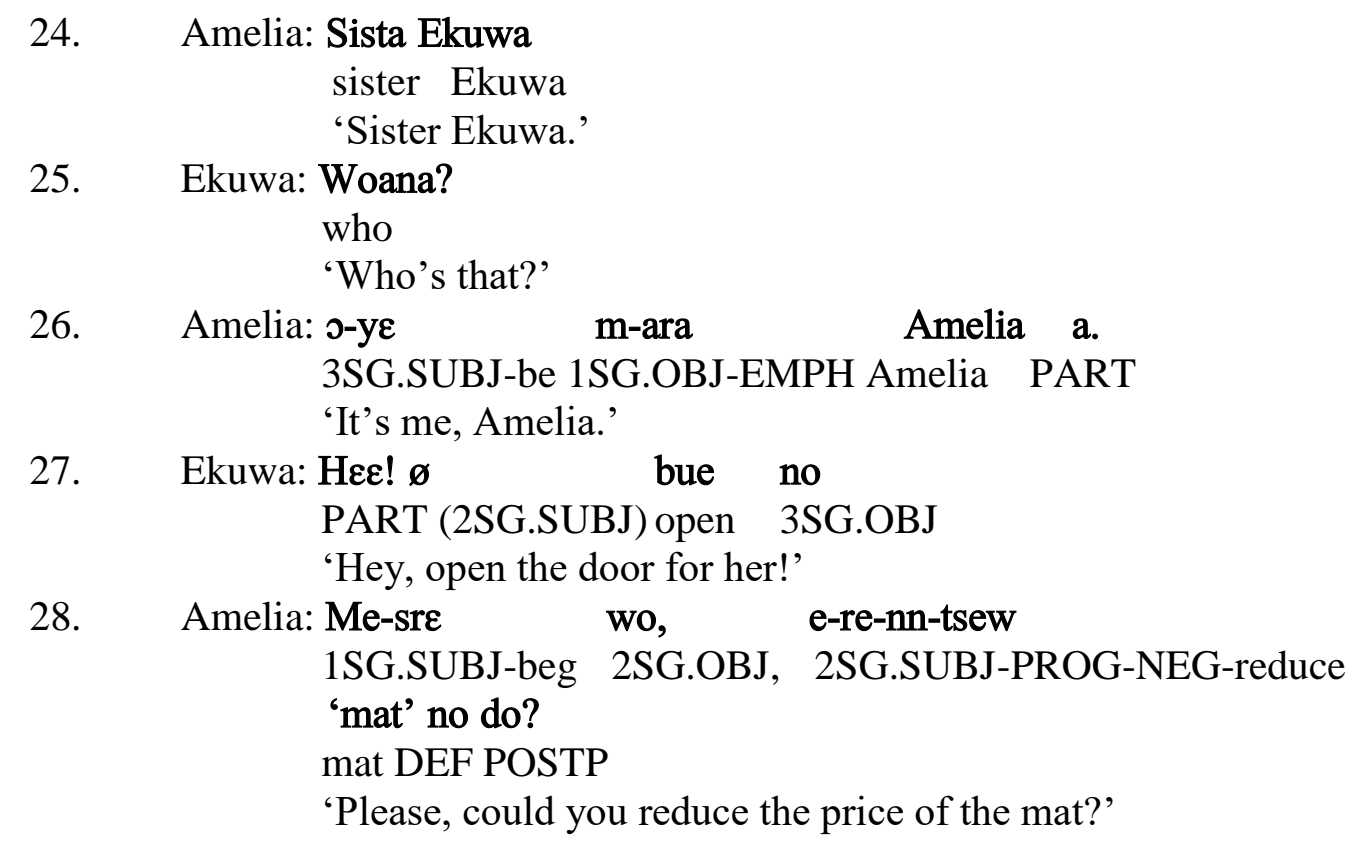

\subsection{Structure of face-to-face casual conversational closings}

Just like Schegloff and Sacks (1973) put it, conversations do not just end; rather, they go through elaborate rituals before they are brought to a close. Determining the structure for closings in face-to-face dyadic casual conversation is not an easy task. Based on the available data, the following structure is identified: announcing closure (Liddicoat, 2007), introducing new topic/recapitulation (Coronel-Molina 1998), future arrangements and transmitted greetings/appreciations, and terminal exchanges. It is very important to note that the proposed procedures for closing do not necessarily occur simultaneously in a single dyadic conversation, just like it is in the opening sequences. These sequences are elaborated below.

\subsubsection{Announcing Closure}

According to Liddicoat (2007), announcing closure is by some external circumstances that force one of the parties to close the conversation. With this phenomenon, as depicted in our data, a conversational participant put forward a claim that makes it obvious that a conversation will have to come to an end. Conversational participants who announce the closure of a conversation mostly use excuses as 
strategies to announce to the other party about his/her intentions. An example of announcing closure is seen in the conversation below:

Dyad 5: A conversation between two friends, Ato and Maanu
29. Ato: $\mathbf{S} \varepsilon \varepsilon-\mathrm{n}-\mathrm{y} \varepsilon$
emi nko.//hh Beebiara

so 3SG.SUBJ-NEG-be 1SG.OBJ alone. everywhere

\section{n-dwe-e.}

NEG-cool-PERF

So I'm not the only one facing that problem. //hh It's not easy anywhere.'

30. Maanu: Nyew oo!

$$
\begin{aligned}
& \text { yes PART } \\
& \text { 'Yes oo!' }
\end{aligned}
$$

31. Ato: Awo dze nkorofo bi re-tweon me, 2SG EMPH people INDEFPROG-wait 1SG.OBJ, ntsi ye-be-san e-hyia ae.

so 3PL.SUBJ-FUT-return CONS-meet PART

'Alright, you, I've some people waiting for me, so we'll meet again ok.'

32. Maanu: Yoo m-a-tse mo okay 1SG.SUBJ-PERF-hear 1SG.POSS brother 'Okay, I hear you my brother.'

33. Ato: ono dze, hwe wo ho do yie.

That EMPH, watch 2SG.POSS.body POSTP well

'Then, take care of yourself!'
34. Maanu: Yoo //Wo
35. Ato: Ekyir yi! back DEM 'Later!' okay// $2 \mathrm{SG}$. also dem ara. 'Okay //you too!' ((Ato and Manu shake hands))
36. Maanu: Yoo, mo nua ok, 1SG.POSS brother 'Ok, my brother.'

In the above example, Ato proposes that because he has some appointment with some people, he has to leave. This proposition could be true or false; but it is an excuse he gave in order to end the conversation. In that regard, Maanu's acceptance brings the 
conversation to an end. They both go ahead to exchange some pleasantries to establish social warmth.

In most cases, as found in the data, the announcement of closure does not directly lead to the terminal exchanges. Other elements of closing occur before the final closing. However, there is a deviant case where an announcement of closure immediately led to the terminal component. That deviant case is shown below:

Dyad 6: The closing sections between two friends (names of interactants were unknown)

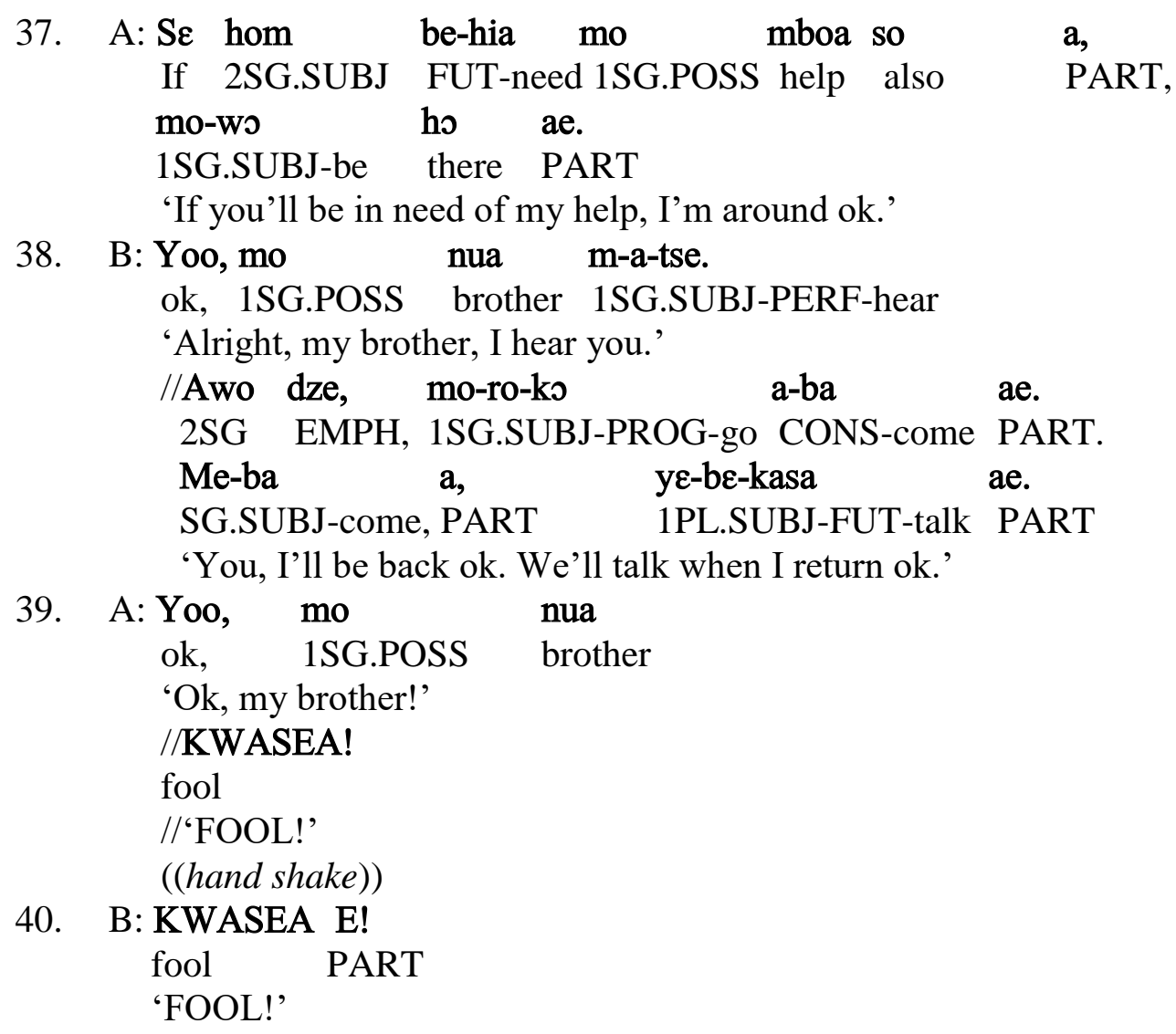

In the above example, Speaker A makes an announcement to close the conversation when he uses the excuse strategy to end the conversation, of which Speaker B accepts. Immediately after the announcement, they shake hands and the terminal exchanges follow. 


\subsubsection{Introduction of new topic/recapitulation}

From the notion of announcing closure, we realized that once an announcement is made, then, a conversation is drawing to a close. However, there are some cases where a conversational participant raises a new topic after an announcement has been made. According to Coronel-Molina (1998), new topic introduction means a topic after a pre-closing gambit. The pre-closing gambit in this case is what has been equated to announcing closure. An example of this phenomenon in the data is dyad 7:

Dyad 7: A conversation between a student and his lecturer-friend in Asante-Twi

41. S: Asuo, $\varepsilon$-ye m'-ahiasem pa

A. $3 S G . S U B J-b e$ 1SG.POSS-important.matter very

ara 00.

EMPH PART

'Asuo, it's of importance to me oh.'

42. L: Wo deع ø-ko na akyire yi na wo-

2SG. TOP (2SG.SUBJ)-go CONJ later DEF CONJ 2SG.SUBJ-

a-ba. M-a-nya ohohos wo fie nti

CONS-come. 1SG.SUBJ-PERF-get visitor at home so

akyire yi bra be-gye.

later DEF come MOT-take

'You go and come later. I have a visitor in the house so come for it later.'

43. S: M-a-te

1SG.SUBJ-PERF-hear

'I hear (you)'

$/ / \mathrm{Na}$ 'machine' no nso wo-a-n-ka ho

CONJ machine DEF also 2SG.SUBJ-PST-NEG-say body

hwee? Anka $\mathrm{m}$ - $\varepsilon$-ba a-be-ye no

nothing? COND 1SG.SUBJ-FUT-come CONS-MOT-do 3SG.

yie a-ma wo.

well CONS-give 2SG.OBJ

'And you didn't say anything about your machine too? I

would have come to repair it for you.'

44. L: Wo de $ø$-bra akyire yi, na ye-n-

2SG.TOP (2SG.SUBJ)-come later DEF CONJ 3SG.SUBJ-IMP-

ka ho asem.

talk body matter

'You, come later and let's talk about it.'

45. S: M-a-te

owura.

1SG.SUBJ-PERF-hear sir 


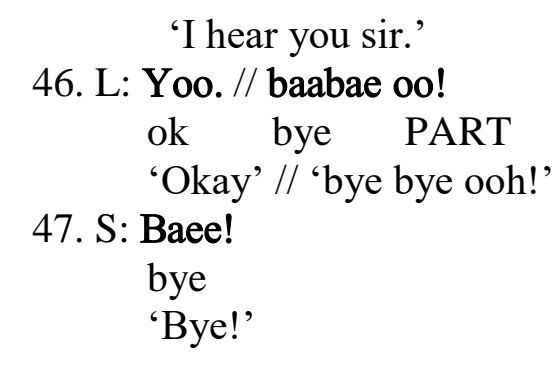

From the above dyad, Speaker L announces closure in line 42 of which Speaker $\mathrm{S}$ accepts. However, immediately after the acceptance of Speaker L's proposal, Speaker $\mathrm{S}$ introduces a new topic in line (43) but the newly introduced topic is put on hold for future discussion.

For recapitulation, conversational participants recall or recollect an earlier conversation either as a reminder or giving a summary of an earlier conversational topic. One thing about recapitulation in the data is that, after a conversational participant recapitulates a conversational topic, it could either lead to other closing sequences like showing appreciation or even final closings. Evidence from the data illustrating this phenomenon is given in dyad 8 below:

Dyad 8: A conversation between two strangers: Stranger $=$ Str., Kuukua $=$ Kuu.

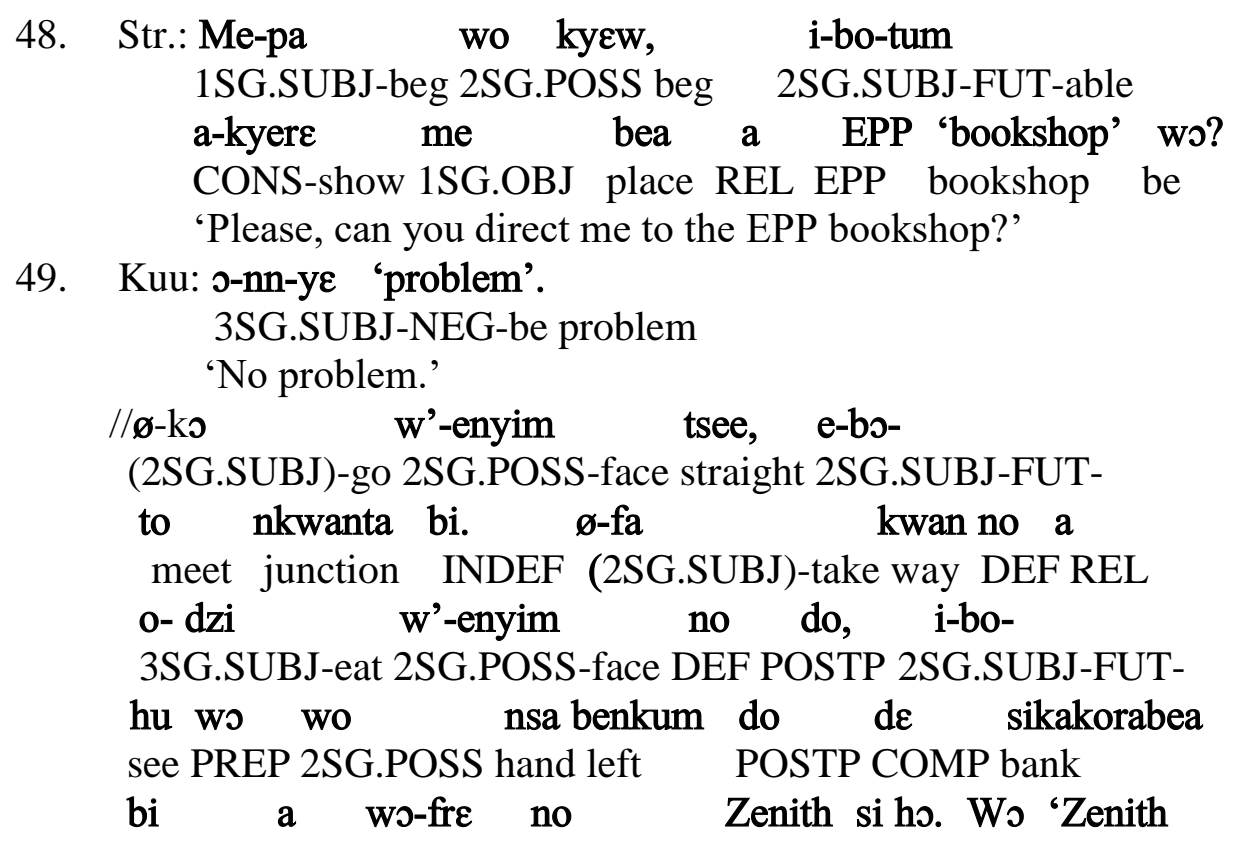


INDEF REL IMP.-call 3SG.OBJ Zenith be there PREP Z. bank' no nkyen ho ara i-bo-hu EPP bank DEF side there EMPH 2SG.SUBJ-FUT-see EPP bookshop no. bookshop DEF

//'Go straight till you meet a T-junction. Take the road ahead of you, on the left-side of the road, you'll see a bank called Zenith Bank. Just beside the bank is the EPP bookshop.'

50.

Str.: Me-da

wo

ase! Me-dze

Laud.

1SG.SUBJ-lie 2SG.POSS under 1SG.SUBJ-call Laud

'Thank you! I'm Laud.'

//Wo so $\varepsilon$ ?

2SG. also Q

//'what about you?'

51. Kuu: Aseda n- nyi ho, Kuukuwa

Thank NEG-be there Kuukuwa

'You're welcome, Kuukua.'

52.

Str.: $\varepsilon$-se mo-n-ko m'-enyim tsee 2SG.SUBJ-say 1SG.SUBJ-IMP-go 1SG.POSS-face straight na mo-bo-to nkwanta bi e-hu? CONJ 1SG.SUBJ-FUT-meet junction INDEF 2SG.SUBJ-see 'You said I should go straight and I will get to a junction, right?'

53. Kuu: Nyew!

yes

'Yes!'

54.

Str.: Na me-m-fa kwan a $\varepsilon$-da

CONJ 1SG.SUBJ-IMP-take way REL 3SG.SUBJ-lie m'-enyim tsentsendo no do, 'bank' bi wo 1SG.POSS-face straight DEF POSTP bank INDEF be me nsa benkum do na ho ara na

1SG.POSS hand left POSTP CONJ there EMPH FOC EPP wo?

EPP be

'Then, I take the road ahead of me, there's a bank on my left and EPP is just there?'

55. Kuu: Nyew. Nara nye no.

yes that be 3SG.OBJ

'Yes. That's it.'

56.

Str.: 0-ye me

ahomka $d \varepsilon \quad$ mi-hyia-a 
3SG.SUBJ-be 1SG.OBJ nice

COMP 1SG.SUBJ-meet-PST

wo.

2SG.OBJ

'It was nice meeting you.'

57.

Kuu: Mo so dem ara

1SG. also that EMPH

'It was nice meeting you too.'

In the above illustration from the data, the Stranger recapitulated in lines 52 and 54. He recollected the information that he was given by summarizing it through interrogation with the other conversational participant, Kuukua. It is observed that immediately after the recapitulation process, the terminal components were exchanged between the conversational participants.

\subsubsection{Future Arrangements and Transmitted Greetings}

In face-to-face dyadic casual conversations, conversational participants may schedule a meeting for a later date or refer to some future interaction that they are supposed to have. Like Schegloff and Sacks (1973) indicated, in arrangements, conversational participants may give directions, arrange for later meetings, offer invitations, make a 'reinvocation of certain sort of materials talked about earlier in the conversation' like 'see you later in the day' and also make a summary of the conversation about to be closed. In spite of the views put forward by Schegloff and Sacks (1973), we have limited the arrangements in our data to arranging for a later meeting and offering invitations. An illustration of a future arrangement in the data is given in dyad 7 above in Asante-Twi (but restated below):

$\mathrm{S}=$ Student, $\mathrm{L}=$ Lecturer

58 .

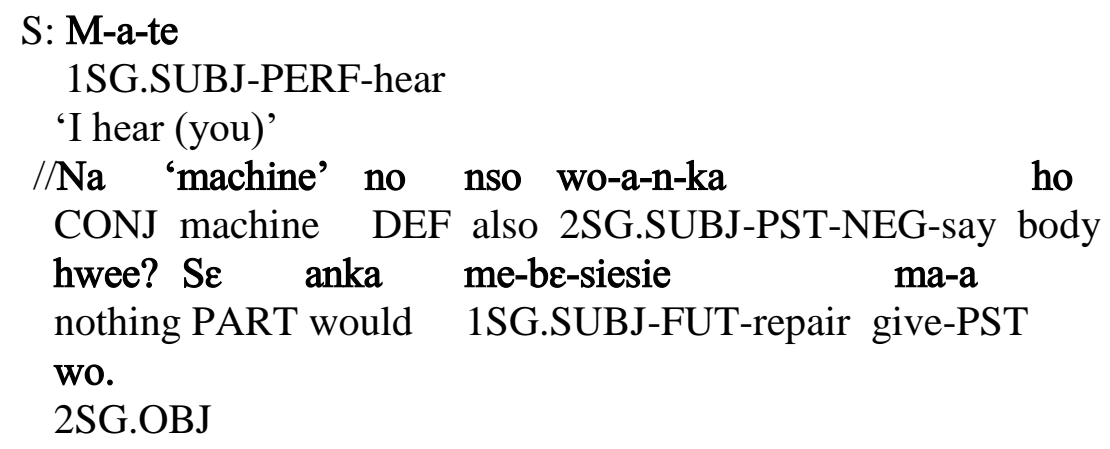

S: M-a-te

1SG.SUBJ-PERF-hear

'I hear (you)'

$/ / \mathrm{Na}$ 'machine' no nso wo-a-n-ka ho

CONJ machine DEF also 2SG.SUBJ-PST-NEG-say body

hwee? $\mathrm{S} \varepsilon$ anka me-be-siesie ma-a

nothing PART would 1SG.SUBJ-FUT-repair give-PST

wo.

2SG.OBJ

'And you didn't say anything about the machine? I would have come to repair it for you.' 
59.

L: Wo de $\varepsilon$, bra akyire yi na ye-n-ka 2SG. TOP come.IMP later DEF CONJ 1PL.SUBJ-IMP-talk

ho asem.

body matter

'You, come later and let's talk about it.'

60.

S: M-a-te

owura.

1SG.SUBJ-PERF-hear sir

'I hear you sir.'

61.

L: Yoo. // baabae oo!

ok bye

62.

'Okay // bye bye ooh!'

S: Baee!

bye

'Bye!'

In the above illustration, it is obvious that Speaker L makes a future arrangement with Speaker S after Speaker S raised a new topic when an announcement had already been made for a closure. Like Button (1987) put it, arrangements make it possible for other potential topics to be dealt with in the future encounter and closing will be likely.

It is also possible for one or both participants to transmit or send greetings after an announcement for closure has been made. In transmitted greetings, a conversational participant extends his/her regards to his co-participant's family. The greetings that are extended to the family could be for the father/ husband, mother/wife of the family or even the children. This form of greeting extension is meant to create, maintain and solidify the bond that exists between a conversational participant and the other members of his/her co-participant's family. Evidence of this form from our data is given in dyad 9 below:

Dyad 9: A conversation between an elderly man and a young man. Papa Kwesi $=\mathrm{PK}$, Young Man $=\mathrm{Adu}$

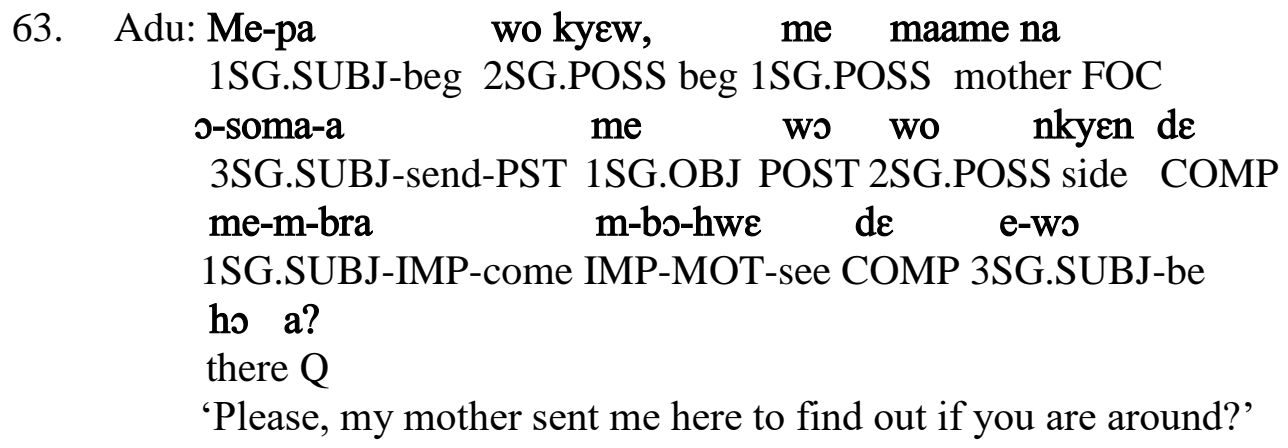


64. PK: Aaa yoo. //e-ko a, ka kyere no d $\varepsilon$ PART ok 2SG.SUBJ-go CONJ tell show 3SG.OBJ COMP mo-wo ho ae.

1SG.SUBJ-be there ok

'Aah okay.' //'When you go, tell her that I'm around, okay?'

65. Adu: Yoo, Egya. //Me-pa wo kyew, ok father 1SG.SUBJ-beg 2SG.POSS beg $\mathrm{m}$ - $\varepsilon$-sre kwan kakra.

1SG.SUBJ-FUT-beg way little

'Okay, Sir. //Please, I would want to take a leave.'

66. PK: 'Yoo'

ok

'Okay'

//ع-ks a, ø-kyea w'-egya

2SG.SUBJ-go CONJ (2SG.SUBJ)-greet 2SG.POSS-father

ma me ø-a-tse?

give 1SG.OBJ (2SG.SUBJ)-PERT-hear

//'When you go, my regards to your father okay?'

67. Adu: Me-pa wo kyew, yoo.

1SG.SUBJ-beg 2SG.POSS beg, ok

'Please, alright.'

68. PK: ono dze baabae!

3SG. TOP bye

'Then, bye!'

69. Adu: baee!

bye

'Bye!'

From the illustrations above, it is observed that Papa Kwesi extends greetings through Adu to be conveyed to his father. Even though Adu's father was not the one to have sent him to Papa Kwesi, Papa Kwesi transmits greetings to Adu's father so as to maintain and solidify a bond that exist between them. It can also be seen from the above conversation that conversational participants can immediately go ahead and terminate the conversational process. 


\subsubsection{Terminal Exchanges}

The terminal exchanges are actually the final remarks that conversational participants make to finally draw the curtain on the conversation. The terminal component could be a goodbye (just like the terminal exchange in any other mode), or others such as thank you. Among Akan conversational participants, the expression, 'yoo', an equivalent of 'okay/alright' in English is mostly used to finally close a conversation. In other cases too, a repeat of a catch phrase could be used to terminate the conversation. A clear evidence of such form is given in dyad 6 above (but restated below):

70. A: Yoo, mo nua
ok 1SG.POSS brother
'Okay, my brother.'
//KWASEA!
fool
'FOOL!'
((hand shake))

\section{B: KWASEA E! \\ fool \\ 'FOOL!'}

So far we have identified five procedures that the closing sequences go through before a face-to-face casual conversation is brought to a close based on our data. These are announcing closure, new topic introduction/recapitulation, future arrangements and transmitted greetings, and terminal exchanges. These procedures can however be categorized into three structural elements. These structural elements are introductory closings which cater for the very procedures that occur at the early stages of the closings (such as announcing closure and new topic introduction/recapitulation), intermediate closings which occur in-between the introductory closings and the final closings (such as future arrangements and transmitted greetings), and final closings which deal with the terminal components that are used to terminate the conversation (such as the terminal exchanges).

\subsection{Juxtaposing the structure of face-to-face casual conversation to telephone conversation model}

Face-to-face and telephone conversation occurs in two different modes but there seem to be some sense of generality in conversational pattern occurring in the two modes. Coronel-Molina's (1998) model for telephone conversation openings and 
closings are not extremely different from the form proposed for the face-to-face conversations. In relation to the openings, the only change that occurs in telephone conversations is in connection with the summon-answer sequence. Apart from this sequence, all other forms of sequences in the openings occur in both modes. There is, however, a considerable change in the closings across both channels. These sequences that seem to differ or recur in different forms are discussed below.

\subsubsection{Juxtaposing Openings in Face-to-face and Telephone Modes}

Coronel-Molina (1998) proposed a canonical order for openings: summonanswer sequence, identification and recognition, greeting token and how-you-are sequence. All these forms of openings recur in the openings of face-to-face conversations except the summon-answer sequence which changes insignificantly.

\subsubsection{Summon-answer sequence vs. presence/absence of interlocutors}

The summon is the signal that catches the attention of another that a talk is (to be) initiated. The response to a summon serves as an answer to the summon. In telephone conversation, there is a fixed summon-answer sequence. Schegloff (1986) points out that in routine cases, the telephone ring functions as the summons, to which the opening utterance, such as 'hello' or identification, is the answer. However, within the context of face-to-face, based on our data, we identified two forms in openings, presence and absence of interlocutors. The absence of an interlocutor is very similar to the situation in the summons-answer in telephone conversation. That is, in the absence of an interlocutor, only one conversational participant is readily available to initiate a conversation. So, for the other person to assume a participant position, the initiator summons the other (this time not by noise such as the ringing of the telephone but by address term) to assume a participant position. The response of the second party to the summons serves as the answer.

The point of contrast here occurs in the situation where both conversational participants are present. In this context, conversational participants use forms such as interrogation, and various forms of addresses as the first signals.

\subsubsection{Interrogation}

Based on the evidence in the data, it is realized that most CPs use interrogations as their first signal so as to attract the attention of the other interlocutor unto himself/herself. It was observed that this form is frequently used when the initiator is approaching from a far distance. An instance from the data collected is given in dyad 11 below:

Dyad 11: A conversation between a woman and her boss' wife. 


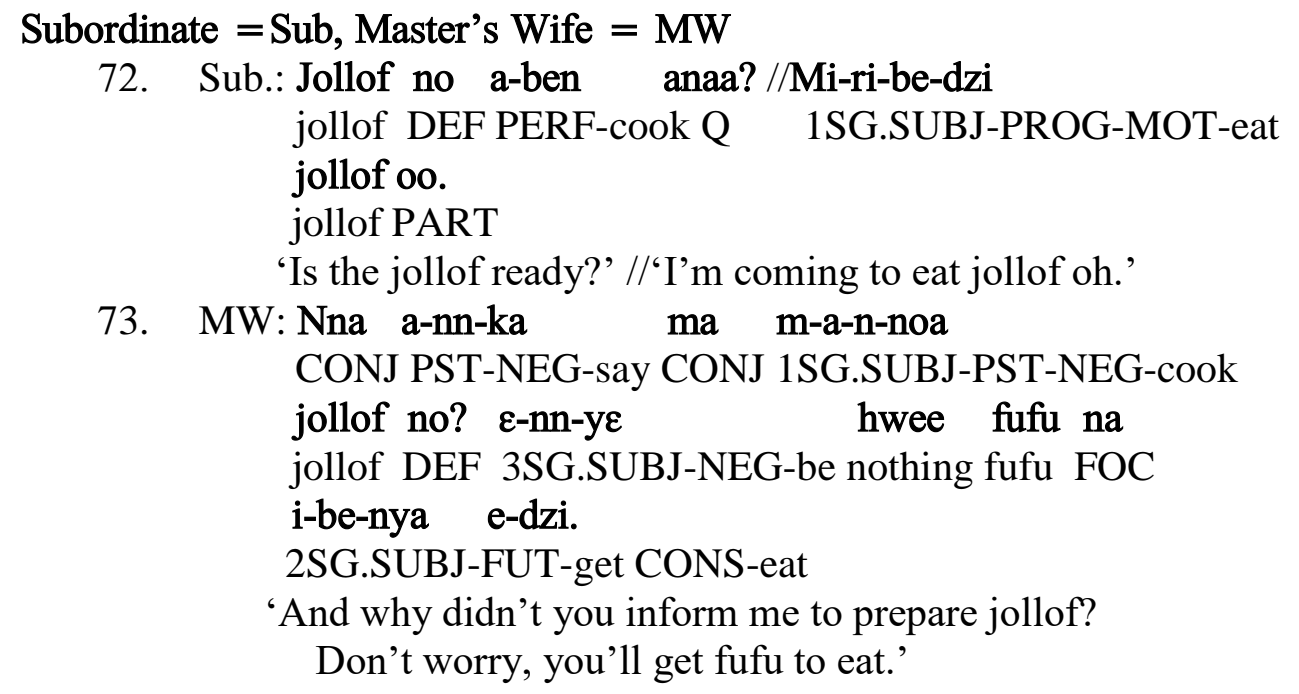

In the above conversation, the subordinate, who is the initiator of the whole conversation (since she is paying the visit), begins with an interrogation so as to draw the attention of the Master's Wife to herself. Master's Wife's response to the signal of the initiator (Sub.) also begins in a rhetorical question. The initiator/addresser used question and not a declarative, imperative or exclamative because she resorted to making a 'playful request'. Thus, the addressee is given options while the 'playful' request is made. This situation of using interrogatives to initiate a talk does not only show politeness but also depicts intimacy.

\subsubsection{Address Forms}

According to Afful (2006), terms of address constitute an important part of verbal behaviour through which the behaviour, norms and practices of a society can be identified. The use of address forms is one of the ways that conversations are initiated in the face-to-face context. According to Oyetade (1995), as quoted by Afful (2006), address terms refer to words or expressions used in an interactive, dyadic and face-toface situation to designate the person being talked to. The forms of address identified in our data are titles plus greeting, first names plus greeting, endearment terms plus interrogation and catch phrases.

In the analysis of the data, one form of address that conversational participants used to initiate a conversation is title plus greeting. From the data, it is realized that an interlocutor may employ title plus greeting when there is a significant age difference or difference in status. Just as Afful (2006) points out, titles are usually associated with hierarchical institutions. Evidence from the data is shown in dyad 12 below: 


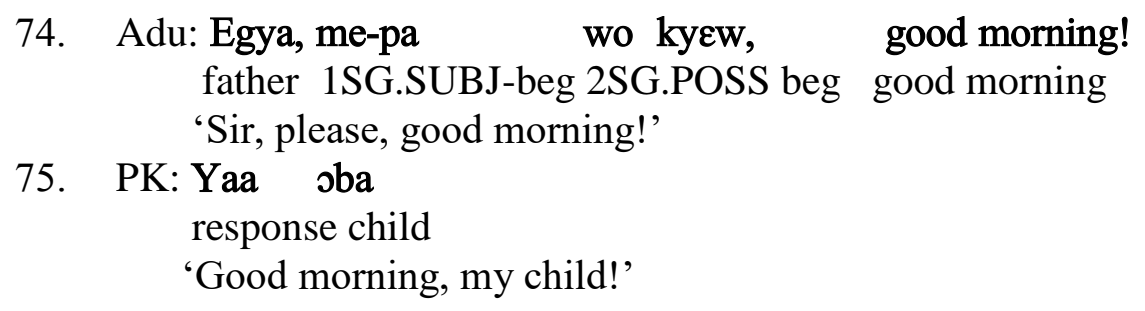

The use of "Egya" (Sir) complementing the greeting in the data above is used to initiate the conversation. Among the Akan, it is impolite to address an elderly without a title or name and even, sometimes, without a courtesy marker 'please'. This, to quote Afful (2006), is markedly used to show deference to the addressee.

As humans who live in societies, every individual has a name that serves as an identity. In initiating a conversation, CPs may use a first name plus greeting. The example below in dyad 13 indicates the use of first name plus greeting to initiate a conversation.

76. Gina: Canon, me-pa wo kyew,

me-ma

canon 1SG.SUBJ-beg 2SG.POSS beg 1SG.SUBJ-give

wo adwe

2SG.OBJ evening

'Canon, please, good evening!'

77. Canon: Yaa oba

response child

'Good morning my child!'

This discourse was carried out between a youth leader, Gina, and her priest, Canon. The addresser, Gina, uses an address term plus greeting complemented with the courtesy marker, 'please' to initiate the discourse. This form, again, indicates how politeness as a cultural value is rooted in Akans in demonstrating deference.

Another way a conversation is initiated is by the use of endearment terms plus interrogation/greeting. According to Frimpomaa (2012), endearment terms are usually soft terms that show affection towards the addressee or the attempt to endear oneself to the addressee. An example in dyad 2 is restated below:

A conversation between two strangers; Stranger $1=\mathrm{S} 1$, Stranger $2=\mathrm{S} 2$

78. S1: ohembaa, me-ma wo
queen




\section{'Dear, Happy New Year!' \\ 79. S2: Afe n-ko m-bo-to hen! \\ year IMP-go IMP-MOT-meet 1PL.OBJ \\ 'Many happy returns!'}

Endearment terms are usually used among friends to show that there is a symmetrical relationship between them. However, in the context of the above dyad, Speakers S1 and S2 are both strangers so the use of the endearment term, shemmea (which literally means queen) is probably performing the function of luring the other conversational participant for a favour. It could also probably be that through the use of that endearment term, a relationship is created among both CPs.

Some CPs also use catch phrases to initiate the conversation. Catch phrases are address terms or mottos used to express transient communicative intent such as sharing a common fate, the mood of the moment or the aim of a group or the invention of particular individuals who are often friends. They function in the same manner in which adjacency pairs function in a conversation. They operate on the basis of callresponse pattern (Afful, 2006). They can be used to begin a conversation as well as end a conversation, as evident in dyad 6 which is restated below:

\section{A: KWASEA BI NTSI! fool INDEF because 'ALL BECAUSE OF A FOOLISH PERSON!' \\ 81. B: KWASEA BI NTSI OO! fool INDEF because PART 'ALL BECAUSE OF A FOOLISH PERSON OH'}

It is obvious in the above that Speaker A and B in a call-response pattern use catch phrases to initiate the conversation. Also, these insults perform the function of greeting among conversational participants. And just as Sekyi-Baidoo (2009) put it, contrary to social breakdowns, insults are also used to foster social cohesion and maintain relationships.

From the discussions above, it is presented that despite the fact that there seem to be some generality in the openings in both face-to-face and telephone modes, the way first signals are sent when both conversational participants are present is different as compared to that of summon-answer sequence in telephone conversations. However, there is no significant difference between the summon-answer sequence in telephone conversations and face-to-face conversation when an interlocutor is absent so far as first signals are concerned. 


\subsubsection{Closing Model in Face-to-face and Telephone Conversations}

Coronel-Molina (1998), in the closing sections proposed some procedures that conversations go through before they are brought to a close. He indicated that before the final closings are issued, CPs prepare the grounds for the terminal exchanges. In that regard, pre-closing gambits like okay/alright are issued so as to offer a CP an opportunity to raise another topic. Coronel-Molina (1998) earlier on posited that because Schegloff and Sacks (1973) did not give precise names to the indicators that lead to the final exchanges. As a result, his telephone model posited new topic introduction and recapitulation as the indicators that Schegloff and Sacks failed to give precise names to.

Terminal exchanges in the telephone mode are not different from that of faceto-face terminal exchanges since the usual goodbye, see you later, thank you and okay/alright all recur in the face-to-face mode. The point of contrast is in the presence of closing sequences like announcing closure, future arrangements and transmitted greetings which are absent in her telephone mode. These sequences were consistently found in the data and it thus, presents a slightly different structure of closings in the two modes.

\section{Conclusion}

The primary objective of this research was to present a description of the structure of face-to-face dyadic casual conversations in the Akan context. Also, since research into telephone conversations served as the bedrock for the research in face-toface conversations, the model for telephone conversation openings and closings were juxtaposed to that of face-to-face dyadic conversation. On the one hand, the study revealed Akan face-to-face casual conversational openings to be in two forms: presence and the absence of interlocutors; and that in whichever case we could have greetings and how-are-you sequence. It was also revealed that identification and recognition only occurred in situations where one party of the yet to be started conversation is not in sight. On the other hand, closings were categorized into three: introductory closings (announcing closure and new topic introduction/recapitulation), intermediate closings (future arrangements and transmitted greetings), and final closings (terminal exchanges). All these sequences, even though are perfunctory, do not occur in a strict orderly pattern.

Finally, in juxtaposing the structure of face-to-face casual conversations to that of telephone conversations, even though the conversations occur in two different modes, (face-to-face and telephone) the study revealed some sense of generality in the 
pattern of conversation across both modes. This, however, brings about some form of universality in the structure of conversations across different modes. We believe that the similar structures in both modes (especially, openings) can be alluded to the fact that, with the advent of technology, the form of conversation that occurs within the face-to-face context was transferred to a mode like telephone. 


\section{References}

Afful, Joseph Benjamin Archibald, 2006. Address Terms among University Students in Ghana: A Case Study. Journal of Language and Intercultural Communication, 6(1), 76-91.

Bou-Franch, Patricia, 2011. Openings and Closings in Spanish Email Conversations. Journal of Pragmatics, 43, 1772-1785.

Button, Graham, 1987. Moving out of Closing. In Graham Button and John R. E. Lee, eds., Talk and Social Organization. Clevedon and Philadelphia: Multilingual Matters.

Calvo, Clara, 1995. Telephone Conversation in the Fiction of Raymond Chandler: Opening Up Openings and Closings. Madrid: UCM Publication Service.

Coronel-Molina, Serafin M. 1998. Openings and Closings in Telephone Conversations between Native Spanish Speakers. Working Papers in Educational Linguistics, 14 (1), 49 - 68.

Firth, John Rupert, 1972. Verbal and Bodily Rituals of Greeting and Parting. In Jean Sybil La Fontaine, ed., Interpretation of Rituals, 1-38. London: Tavistock.

Frimpomaa, Kate Kwakye (2012). Politeness among University Students: A Case Study of University of Cape Coast. Unpublished B. A. Dissertation, University of Cape Coast, Cape Coast.

Hopper, Robert, 1989. Sequential Ambiguity in Telephone Openings: "What are you Doing". Communication Monographs, 56 (3), 240-252.

Jefferson, Gail, 1984. Transcript on Notation. In J. Maxwell Atkinson \& Heritage, John, eds., Structures of Social Action. Cambridge: Cambridge University Press, ix-xvi.

Kiss, Eva, 2002. Conversational Opening and Closing. Munich: GRIN Publishing.

Liddicoat, Anthony J., 2007. Closing Conversation: An Introduction to Conversational Analysis. London: Continuum.

Malinowski, Branislaw, 1923. The Problem of Meaning in Primitive Languages. In Charles Kay Ogden and Ivor Armstrong Richards, eds., The Meaning of Meaning (pp. 146152). London: Routledge \& Kegan Paul.

Malinowski, Branislaw, 1926. Crime and Custom in Savage Society. London: Kegan Paul, Trench and Trubner.

Oyetade, Solomon Oluwole, 1995. A Sociolinguistic Analysis of Address Forms in Yuroba. Language in Society, 24, 515-535.

Paltridge, Brian, 2008. Discourse Analysis (3rded.) Maiden, U.S.A: Continuum.

Placencia, Maria Elena, 1997. Opening up Closings - the Ecuadorian Way. An Interdisciplinary Journal for the Study of Discourse, 17(1), 53-81.

Prace, Dizertacni, 2009. Language of Internet Relay Chat: Reconsidering Politeness and Impoliteness in the Context of IRC. Retrieved November 11, 2013, from http://is.muni.cz

Raclaw, Joshua, 2008. Two Patterns for Conversational Closings in Instant Message Discourse. Colorado Research in Linguistics, 21. 
Saadah, Eman, 2009. The 'How Are You?' Sequence in Telephone Openings in Arabic. Studies in the Linguistic Sciences: Illinois Working Papers, 171- 186.

Sekyi-Baidoo, J. Yaw, 2009. Insults and Social Cohesion: A Case Study of Student Relationships at the University of Cape Coast, In GHAJPT, 5.

Schegloff, Emmanuel A., 1968. Sequencing in Conversational Openings. American Anthropologist, 70, 1075-1095.

Schegloff, Emmanuel A., 1979. Identification and Recognition in Telephone Conversation Openings. In George Psathas, ed., Everyday Language: Studies in Ethnomethodology. New York: Irvington Publisher, 23-78.

Schegloff, Emmanuel A., 1986. The Routine as Achievement. Human Studies, 9, 111-151.

Schegloff, Emmanuel A., and Sacks, Harvey, 1973. Opening up Closings. Semiotica, 8 (3), 289-327.

Silvia, Arnis, 2012. Conversation Analysis and the Structure of Conversation. Paper Presented as an Assignment for Sociolinguistics Class, UIN Syarif Hidayatullah Jakarta, Indonesia.

Sun, Hao, 2005. Collaborative Strategies in Chinese Telephone Conversation Closings: Balancing Procedural Needs and Interpersonal Meaning Making. International Pragmatics Association, 15 (1), 109 - 128.

Taleghani-Nikazm, Carmen, 2002. A Conversation Analytical Study of Telephone Conversation Openings between Native and Nonnative Speakers. Journal of Pragmatics, 34, 1807-1832.

Verderber, Rudolph F., 1981. Communicate! (6thed.) California: Wadsworth Publishing Company. 